\title{
Investigation of Mechanical Properties of Metal Inert Gas-Brazed TRIP800 Steel Joints Using Different Shielding Gas Flow Rate
}

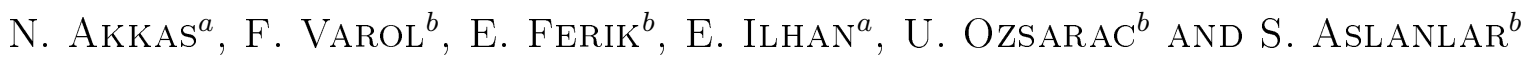 \\ ${ }^{a}$ Department of Mechanical Engineering, ${ }^{b}$ Department of Metallurgical and Materials Engineering \\ Sakarya University, Faculty of Technology, 54187, Sakarya, Turkey
}

\begin{abstract}
In this study, TRIP 800 (transformation induced plasticity) steel plates having $1.5 \mathrm{~mm}$ thickness were joined by copper-based $(\mathrm{CuAl} 8)$ wire in gas metal arc brazing technique. Specimens were prepared in joining forms as butt joint. Brazing operations were done with five different shielding gas flow rates of $8,10,12,14$, and $16 \mathrm{~L} / \mathrm{min}$. CuAl8 wire composed mostly of copper serves as the filler metal. Having accomplished the brazing operations, tensile properties of joints were detected, and micro- and macrostructures of joints were investigated in order to see the joinability of TRIP 800 steel by gas metal arc brazing technique.
\end{abstract}

DOI: 10.12693 /APhysPolA.125.473

PACS: $81.20 . \mathrm{Vj}$

\section{Introduction}

Transformation induced plasticity (TRIP)-aided multiphase steels are a new generation of low-alloy steels that exhibit an enhanced combination of strength and ductility, thus satisfying the requirements of automotive industry for good formable high-strength steels. This excellent strength-ductility combination results from the presence of multiphase microstructure consisting of bainite, and retained austenite in a continuous soft ferrite matrix. When the necessary activation energy is induced during deformation, the retained austenite transforms to martensite significantly improving the work hardening of the material [1]. The TRIP effect was first investigated by Zackay [2]. The TRIP steels are characterised by a relatively low content of alloying elements. For example, TRIP800 steels used in this study contain only the $3.5 \mathrm{wt} \%$ total content of alloying elements. The chemical composition of the traditional TRIP steel is 0.1$0.4 \mathrm{C}-1.5 \mathrm{Mn}-1.5 \mathrm{Si}$ [3]. Carbon increases the stability of austenite so austenite can be found as retained to below ambient temperature. Manganese is an austenite stabilizer and it lowers the cementite start temperature. It also lowers the carbon activity in austenite and ferrite and increases the carbon solubility in ferrite. Silicon significantly increases the carbon activity in both ferrite and austenite and decreases its solubility in ferrite $[4,5]$.

The car assembly industries have recently been using zinc-coated carbon steel sheets in passenger car bodies because they combine good mechanical properties, good corrosion resistance and low purchase cost of this material [6]. Galvanized TRIP steel sheets are widely used in construction with corrosion resistance and especially in the automotive industry [7]. To reduce the risk of zinc evaporation, new welding processes with a low heat supply have begun to gain ground, for example metal inert gas (MIG)-brazing, which combines the advantages of the MIG process (e.g. high deposition rate, high welding speed and adaptability to automation) and brazing (i.e. without any intense fusion of the welded parts and without any appreciable alteration of the mechanical properties of the base metal and the coating applied) [8]. MIG-brazing of galvanized steel sheets was studied using copper based filler and it is found that the joint strength is higher than that of the base materials $[9,10]$. In present paper, the effect of MIG-brazing process on joint strength and microstructure of galvanized steel joints were investigated.

\section{Material and method}

In this study TRIP 800 steel, one of the TRIP series used in automotive industry, was chosen and joined with MIG brazing technique. In the tests the steel plates were $1.5 \mathrm{~mm}$ thickness, with $7.5 \mu \mathrm{m}$ zinc coating. The filler metal was a solid wire with a diameter of $1 \mathrm{~mm}$, classified as AWS ERCuAl8, which is a copper-based, working angle of $90^{\circ}$. MIG brazing operations were carried out in a current control MIG welding machine having $300 \mathrm{~A}$ capacities. Argon was used as the shielding gas at flow rates of $8,10,12,14$, and $16 \mathrm{l} / \mathrm{min}$. The surface of the samples was cleaned by acetone before MIG-brazing operation. All MIG-brazing applications were performed automatically with a speed controlled arm by using a specially designed welding machine.

\section{Experimental results and discussions}

Steel plates were joined by MIG-brazing in butt joint form. In each form, different shielding gas flow rates were used and tensile tests were applied. The results were given in the diagram below.

\subsection{Tensile test results}

In this study, gas flow rate and maximum tensile stress were handled as two important parameters. The relationship of these parameters was given in Fig. 1. 


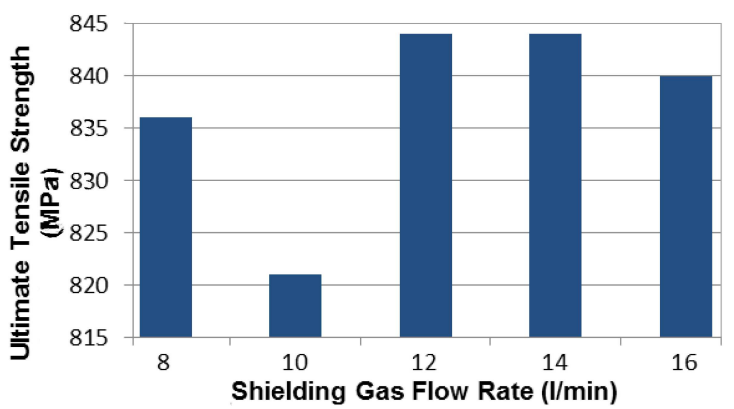

Fig. 1. Tensile test results.

\subsection{Microstructure}

Optical microstructure of MIG-brazed TRIP showed diffusion of micro iron particles in copper based braze metal as shown in Fig. 2a,b. Having examined the scanning electron microscopy (SEM) images in Fig. 3, forms of dendrites occurring in the brazed metal were seen. The interface between base metal and copper bead has also been investigated. A very fine layer can be observed at the interface. The chemical composition of the layer was investigated by using SEM and EDS analysis, as shown in Fig. 3 and Table, respectively. The interface layer is mainly composed of iron, copper, and other alloying elements present in the filler wire (Al). Figure 3 also shows that dendrites grow in the copper matrix starting on this interface layer.
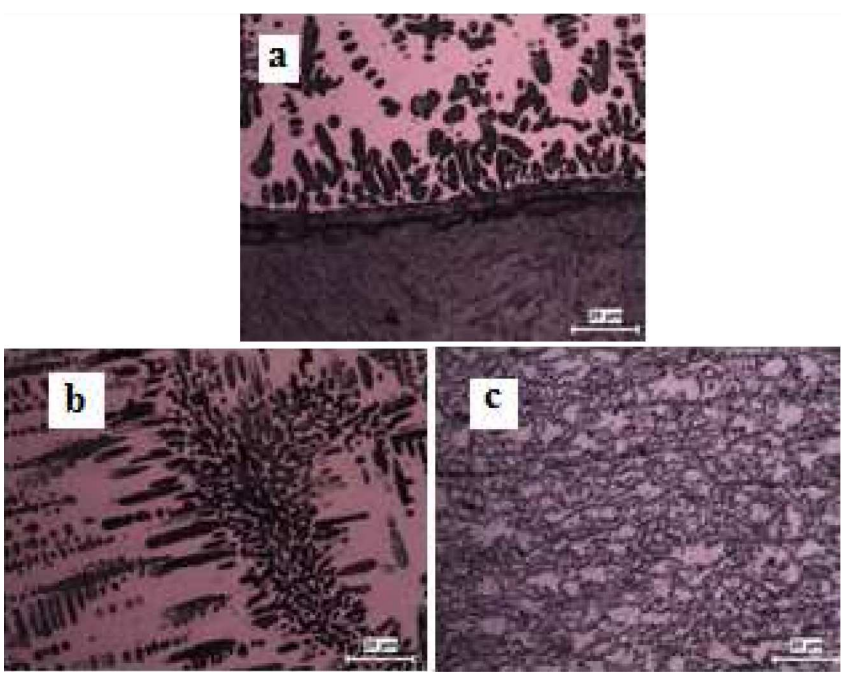

Fig. 2. Mig-brazed TRIP 800 microstructures: (a) interface, (b) braze, and (c) base metal microstructure.

TABLE

The chemical analysis of the points seen in SEM micrograph (wt\%).

\begin{tabular}{c|c|c|c|c|c}
\hline \hline Point & $\mathrm{Al}$ & $\mathrm{Si}$ & $\mathrm{Mn}$ & $\mathrm{Fe}$ & $\mathrm{Cu}$ \\
\hline 1 & 3.382 & 2.2876 & - & 83.005 & 11.326 \\
2 & 5.837 & 1.852 & - & 77.323 & 14.988 \\
3 & 11.782 & 6.293 & - & - & 81.925 \\
4 & - & 2.488 & 1.106 & 91.228 & -
\end{tabular}

The chemical analysis of the brazed joint was shown in Table. During the arc brazing process, it was observed that the number of dendrites increased on the surface of the joint zone. These dendrites' action caused micro iron particles to melt and migrate, and to become distributed throughout the filler metal zone.

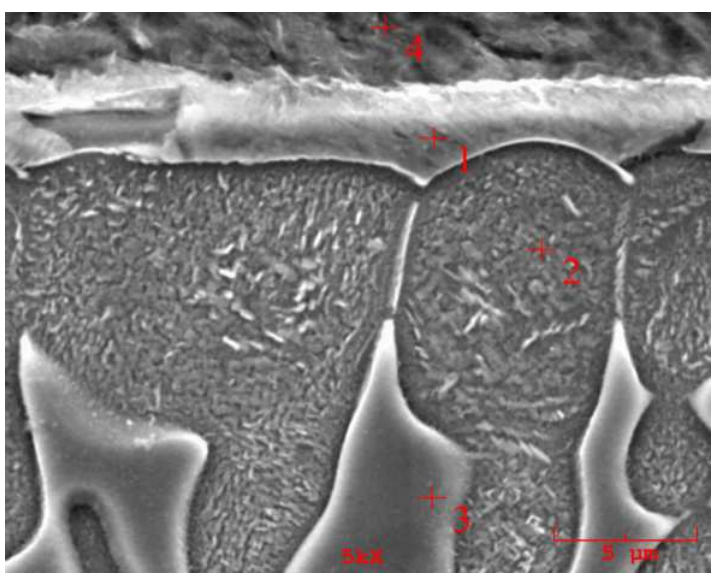

Fig. 3. SEM image of the brazed seams.

\section{Conclusions}

The joinability of TRIP 800 steel with filler metal was examined with MIG-brazing method and it was proved that the base metal was not affected from melting failure. 10 l/min shielding gas flow rate in MIG-brazing operation was a critical point in decrease of spatter in the filler metal and increase of ultimate tensile strength.

\section{Acknowledgments}

The authors wish to thank Sakarya University Scientific Research Foundation (project number: 2010-05-06-008) for their support.

\section{References}

[1] I.D. Choi, D.M. Bruce, S.J. Kim, C.G. Lee, S.H. Park, D.K. Matlock, J.G. Speer, ISIJ Int. 42, 1483 (2002).

[2] V.F. Zackay, E.R. Parker, J.W. Morris Jr. G. Thomas, Mater. Sci. Eng. 16, 201 (1974).

[3] M. Zhang, L. Li, R.Y. Fu, D. Krizan, D.C. Cooman, Mater. Sci. Eng. A 438-440, 296 (2006).

[4] D.C. Cooman, Curr. Opin. Solid State Mater. Sci. 8, 285 (2004).

[5] S. Oliver, T.B. Jones, G. Fourlaris, Mater. Character. 58, 390 (2007).

[6] J. Bian, Y. Zhu, X.H. Liu, J. Iron Steel Res. Int. 13, 47 (2006).

[7] AWS. Welding Processes, Welding Handbook, Vol. 2, 8th ed., AWS, Miami 1991.

[8] A.F. Rangel, L.A. Matlakhova, R.P. Da Rocha Paranhos, A.N. Malakhov, Weld. Int. 20, 889 (2006).

[9] R.F. Li, Z.S. Yu, K. Qi, T. Nonferr. Metal Soc., 397 (2006).

[10] Z.S. Yu, Y.Y. Qian, R.F. Li, F.M. Zhou, Mater. Sci. Technol. Lond. 10, 1399 (2003). 